\title{
Evaluation of Genius for Investing Venture Capital
}

\author{
Shuqiao Zhang ${ }^{1, *}$ \\ ${ }^{1}$ University of Illinois at Urbana-Champaign, Urbana, U.S. \\ ${ }^{*}$ Corresponding Author. Email: shuqiao2@illinois.edu
}

\begin{abstract}
Venture capital is crucial to startup businesses. This paper evaluates whether the startup business Genius is worth investing in by venture capitalists by employing PEST analysis and the POCD framework. The PEST analysis indicates that Genius can be more profitable in the future by examining the effects of political, economic, social, and technological factors on this company. The POCD framework finds that Genius can be profitable and more competitive in the future by providing perspectives from people, opportunities, and context. In general, this startup company is worth investing, as it will be profitable to the venture capitalists.
\end{abstract}

Keywords: Venture capital, Startup business, POCD framework, PEST analysis.

\section{INTRODUCTION}

Venture capital serves as an imperative part of startup businesses. According to Lerner and Nanda [1], seven of the top eight firms by market capitalization in May 2020 had been backed by venture capital before their initial public offerings. Furthermore, firms that are backed by venture capital represent nearly half of entrepreneurial companies that graduate to the public marketplace. Venture capital plays an important role in a company's stage when the company's innovation is being commercialized; a startup company needs venture money until it reaches a sufficient size and credibility so that the institutional public-equity markets can step in and provide liquidity [2]. According to Chemmanur et al. [3], firms financed by venture capital have higher efficiency in gains and are more prone to have successful exits. Puri and Zarutski [4] also found that firms backed by venture capital are less likely to fail in their early stages compared to non-VC financed firms. Venture capital assists startup companies not just as a financial intermediary; venture capitalists usually also provide professionalization measures to the firms to have successful exits [5]. Therefore, it is significant to determine the profitability of a startup business and determine if it is worth investing for entrepreneurs and venture capitalists to be successful.

This paper evaluates the potential success and profitability of the company Genius and attempts to examine whether it is worth investing in. I use the PEST analysis and the POCD framework to investigate the company's extrinsic environment, the market it operates in, and the specific conditions that could affect its success.
Based on the PEST analysis, I have found that the political factors in the United States are beneficial for its management development, and the economic factors are advantageous for its future profitability. The business will be increasingly relevant under the social and cultural context while employing technological improvements and innovations. From the POCD framework, it is found that this company has a group of qualified and dedicated members and thrives in a favorable environment with respect to the general industry, the competition, and the contexts. This paper proposes that Genius is a company with a large potential to be profitable and is worth investing in.

The remainder of the paper is organized into four sections. Section 2 provides a brief history and the description of the company Genius; Section 3 evaluates the company by applying the PEST analysis; Section 4 employs the POCD framework on the analysis of the business; Section 5 presents the paper's conclusion.

\section{FIRM DESCRIPTION}

Genius is a digital media company that was founded in 2009. It was originally founded as an annotation tool for hip-hop music and relaunched in 2014 to include other genres of music and focused on the interpretation and annotation of music lyrics and production. It is a company that strives to make music understandable and make music lovers know the context and production of music [6].

In recent years, it has also started to host live events of artists on its website. Genius has monetized its website 
and YouTube channel through video series with artists and producers breaking down their music. It has produced custom programs for brand partners such as Adidas, Marvel Studio, and Dropbox. It has also established partnerships with music streaming services such as Apple Music and Spotify. Selling collaborated merchandise on its website is another way for Genius to earn revenue. Genius right now has 125 million monthly global visitors on its website and 10 million subscribers on YouTube.

With the development, this firm has attracted lots of attention from investors. The company has collected 77.7 million dollars of venture capital in funding over 6 rounds since 2009. The latest funding was raised from a VentureSeries Unknown round on Sep 11, 2020. Table 1 shows the detailed funding information.

Table 1 Funding Rounds

\begin{tabular}{lll}
\hline $\begin{array}{l}\text { Announced } \\
\text { date }\end{array}$ & $\begin{array}{l}\text { Transaction } \\
\text { Name }\end{array}$ & $\begin{array}{l}\text { Money } \\
\text { raised }\end{array}$ \\
\hline Sep 11, 2020 & Venture Round & $\$ 5.8 \mathrm{M}$ \\
Mar 7, 2018 & Venture Round & $\$ 15 \mathrm{M}$ \\
Jul 11, 2014 & Series B & $\$ 40 \mathrm{M}$ \\
Oct 3, 2012 & Series A & $\$ 15 \mathrm{M}$ \\
Sep 11, 2011 & $\begin{array}{l}\text { Convertible } \\
\text { Note }\end{array}$ & $\$ 1.9 \mathrm{M}$ \\
\hline
\end{tabular}

In 2011, the company collected 1.9 million in convertible notes. In 2012 and 2014, the company has received 15 million dollars and 40 million dollars of venture capital respectively in series A and series B. Then, the company has raised 15 million dollars and 5.8 million dollars in venture rounds of 2018 and 2020, respectively.

\section{PEST ANAlysis}

PEST analysis is a macro external environment analysis that contains four sectors of the taxonomy of the environment: political, economic, social, and technological [7]. This analysis investigates the effects that the political environment has on the specific business, such as government policies, political power structure, and global trade regulations. The economic sector mainly examines the influence of the economic environment on the business; some of the economic factors include industry growth, economic policies, demographics, and globalization. The social analysis looks into detecting socio-cultural trends and changes and estimating the effects on the business. Social factors include cultural trends, consumer attitudes and choices, and changes in demographics. The technological analysis investigates the impact of technologies on the business and takes development and innovations into consideration. PEST analysis helps to identify external impacts that firms may experience in the future, evaluate potential risks, and make strategists understand ways that firms can employ to adapt to the environment [8]. This paper uses the PEST analysis to evaluate the company's profitability by taking a more extrinsic perspective.

\subsection{Political Factors}

Genius is a company that mostly operates online in terms of political factors, therefore not subject to global trade restrictions and other political power structure changes. As the company is based in the United States, it is easy for the company to attract consumers. Music listeners do not have much access to music lyrics and interpretations in this country; Genius can attract traffic and use the online traffic to generate income. There are very strict copyright laws in the United States, so many interpretations on the Genius platform can be protected from other lyric websites and limit competition. Furthermore, there are relatively high barriers to entry for lyric websites, as every lyric website must get copyrights from music production companies to post lyrics.

\subsection{Economic Factors}

The business is relatively less susceptible to economic changes for it operates online and does not mainly depend on its actual merchandise. Its marketing method is mostly business to business. Therefore individuals' buying decisions do not have much influence on this company. The company would also be less susceptible to demographic changes because music listeners would always need to understand and interpret music. As shown in Figure 1, music streaming revenue has increased over the years and accounted for $83 \%$ of the U.S. music industry's revenue in 2020. Other formats such as physical music format, digital downloads, and synchronization have decreased over these years. This is beneficial to Genius because having partnerships with music streaming services is one of its operations. Having more people using streaming services also means that more people have access to lyrics functions and could increase traffic to the Genius website. 


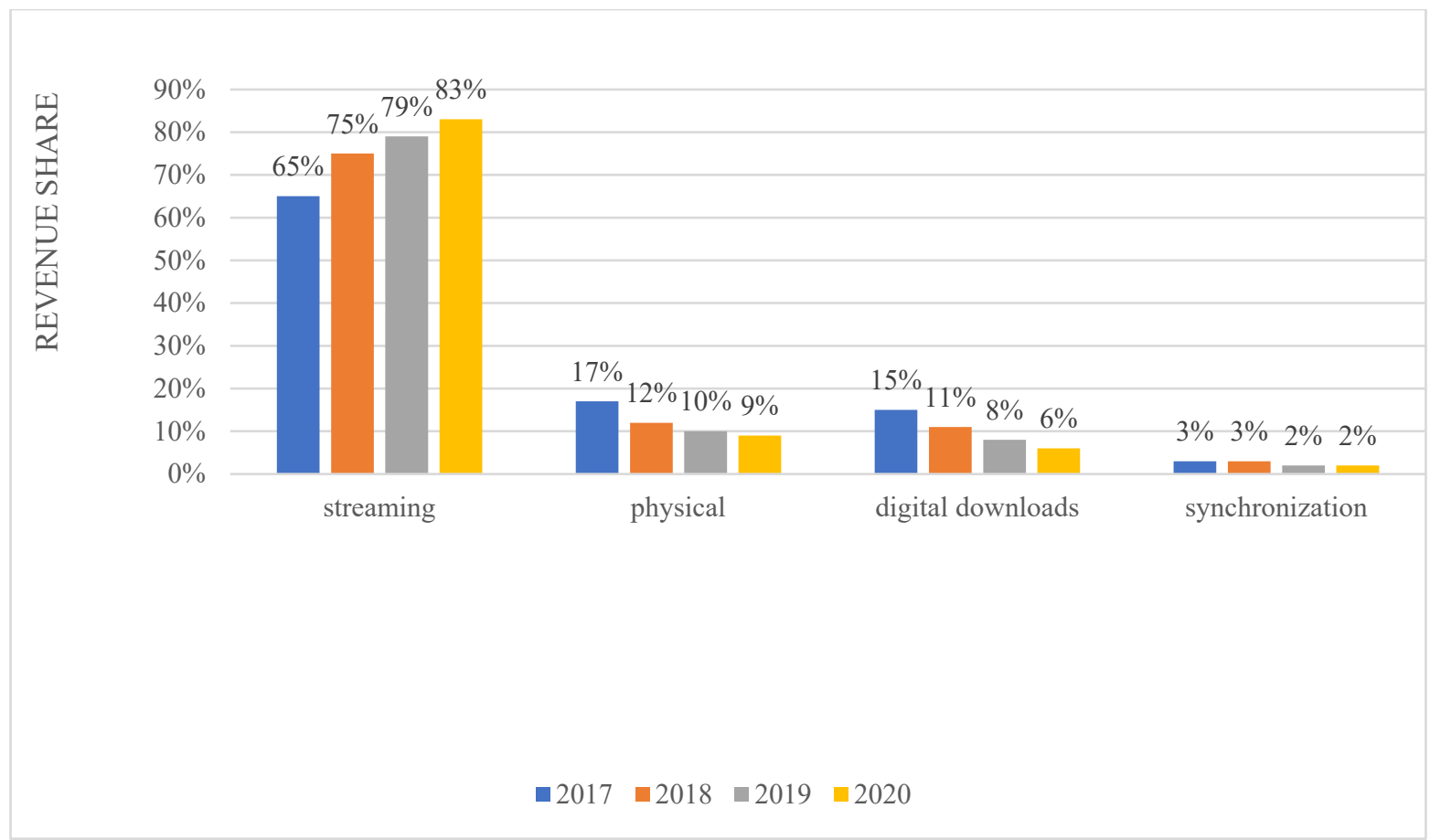

Figure 1 U.S. Music Industry Revenue

\subsection{Social Factors}

For the social factor, many artists, music lovers, and music producers are part of the connections of Genius, and they are willing to contribute to the website to inform music lovers of their production process, inspirations, stories behind the lyrics, or their interpretations of the music. Artists are constantly drawn to this website to contribute and collaborate, while music streaming services need to collaborate with Genius to be more appealing to music listeners. Genius is one of the first companies to expand this music culture. Therefore it has a huge advantage socially. Social factors would have more of an impact on this business. It is possible that this business can be unaffected by other negative changes in the political and economic context.

\subsection{Technological Factors}

Genius has perfected and developed many technological functions over the years and proved that it could be technologically adaptable. For example, facing the accusations of potential abuse has created a function that could report abuse if accidents occur. It has also developed iOS and Android apps for mobile users and has attracted more users from then. Genius has a great calculated platform for allowing and encouraging people to contribute to its website and has a well-maintained technological system. By having multiple social media accounts and having millions of followers on these accounts, Genius can easily fit the technological change to advertise and fit a changing context. This business can innovate its products and services through evolving technologies.
Therefore, it is reasonable to conclude that Genius is a company that can be profitable and is worth investing in. A lot of the factors from the political environment do not have negative impacts on Genius. In contrast, some of the political factors would only influence the company positively, such as the company can be more competitive because of copyright laws. The economic environment is beneficial for Genius to grow in the future because there is a large room for gaining profits. The firm's advantages in social and technological factors could help it to fit new contexts. This paper applies the POCD framework to further examine the profitability of Genius.

\section{POCD FRAMEWORK ANALYSIS}

The POCD framework comprises four parts, people, opportunity, context, and deal [9]. People examine whether the people in this company have the right experience and skills to succeed. The opportunity provides perspectives towards the market and the customers while also examining costs and competition to estimate the potential for success. Context investigates the macroeconomic environment and conditions that influence the opportunity, such as regulations and technology. This paper examines the company's strengths and weaknesses in each of the factors to evaluate its potential for success.

\subsection{People}

The people in this company have the right experience, skills, and attitudes to add the probability of success to the company. Firstly, the original team members showed their dedication as they were passionate enough to leave 
their jobs in their field of study and start to work on the website full time at the earliest stage. Secondly, the team gradually started to gain experience and skills as they welcomed new members; in recent years, some executives were replaced by people with experience in entertainment, music industries, and business development. It shows that the team is willing to adapt to the market and recruit other high-quality members if the original members leave. Furthermore, the team has a good network. It can attract many artists through its reputation, as the artists contribute to the website by interpreting their music and inspirations. Other music lovers and scholars also contribute to the site by signing up for accounts even though the team had faced penalties and adversities in the past, such as when Genius was accused of unlicensed online publication and faced concerns about its extension being susceptible to abuse. They were able to improve and eventually recover from these situations by entering into licensing agreements with music publishers and developing report abuse function on its software.

\subsection{Opportunity}

There is a great opportunity right now for the firm to be successful as the company has advantages in acquiring customers and the potential to prevent competition. Firstly, the total market of music and entertainment is very large as almost everyone listens to music and more people are influenced by pop culture. As there are no lyrics or interpretations of songs or music production processes available from music streaming services, music listeners have to find the information elsewhere; Genius happens to take advantage of this unserved niche in the market. Furthermore, Genius has diversified strategies to expand its business and has incorporated many functions over the years other than interpreting lyrics. After implementing these diversified strategies through ad monetizing from video series with artists breaking down their music, selling merchandise on the website, producing custom programs for brand partners, and partnering with music streaming services. Genius has collected \$10 million of revenue in 2017 and has 125 million monthly global visitors today.

Genius can differentiate itself from other competitors such as LyricFind and Musixmatch because it builds a different and loyal customer base with its unique functions. Furthermore, according to Lim and Benson [10], the dynamic processes associated with Genius's annotations are different from other lyric websites. This technological aspect makes Genius much more competitive in the industry compared with other businesses. It would also be more profitable if the company sells the business directly to customers instead of working with other businesses.

\subsection{Context}

Today's context is beneficial for this company to be successful; it also has the potential to be competitive in a future context. There is a growing demand for knowing the meaning behind the lyrics and how music was made. More genres of music of different languages are being produced with artistic and poetic lyrics. As Genius collects more traffic on its website, more companies are willing to work with it and spread music knowledge. The strong music culture of Genius has attracted many celebrities to invest in this company. Genius has released its iOS and Android app in recent years, which has helped increase its traffic as more people have been using their phones more often. As music becomes more international, Genius has also decided to expand its business to Europe as it partnered up with a Europe-based digital media advertising company. There could be more competitors in the future as the idea to interpret music would not be new soon. However, entry barriers are relatively high because of publishing rights and collaboration deals with verified artists. It is also necessary for Genius to build its brand power to have loyal customers.

Based on the above analysis, I propose my insight about whether to invest in this firm. The team faced various challenges in the company's early years but has strived to possess good skills, attitudes, and reputation. Although it is in a competitive industry, its uniqueness has the potential to build itself a different customer base from its competitors. Genius also can change its marketing method to directly selling to the consumers to be much more profitable. Furthermore, Genius fits today's context in the global world with increasing demand for music knowledge. Overall, Genius has positive prospects, and I would consider investing in the company.

\section{CONCLUSION}

With the growing importance of venture capital in startup businesses, there is a demand for evaluating the potential of success for companies requiring venture capital assistance. The company Genius is a startup business that has raised money from various funding rounds of venture capital. This paper employs the PEST analysis and the POCD framework to estimate the potential of this company's profitability and whether it is worth further investing.

Based on the PEST analysis, it is sensible to conclude that, from the perspective of a macro external environment, Genius has a large potential to be successful in the market, as it has advantages in political, economic, social, and technological sectors while being indifferent towards many of the challenges in these sectors. The POCD framework indicates that while Genius may face challenges, it has a much larger potential to successfully overcome the present obstacles. 
Therefore, Genius is a company that is worth further investing in because the analysis shows that it has the potential to be more profitable in the future.

This article has two aspects of limitation. One of the shortcomings of this paper is that there is not enough available data for analyzing the trends of a more specific revenue of the company throughout recent years. Secondly, the revenue distribution of the company is also unclear. Therefore it is difficult to decide what the company currently focuses more heavily on, which affects the accuracy of the evaluation. In the future, I could collect more information on the company as more data becomes available to have a more exhaustive analysis of the company.

\section{REFERENCES}

[1] Lerner, J., \& Nanda, R. (2020). Venture capital's role in financing innovation: What we know and how much we still need to learn. Journal of Economic Perspectives, 34(3), 237-61.

[2] Zider, B. (1998). How venture capital works. Harvard business review, 76(6), 131-139.

[3] Chemmanur, T. J., Krishnan, K., \& Nandy, D. K. (2011). How does venture capital financing improve efficiency in private firms? A look beneath the surface. The Review of Financial Studies, 24(12), 4037-4090.

[4] Puri, M., \& Zarutskie, R. (2012). On the life cycle dynamics of venture-capital-and non-venturecapital-financed firms. The Journal of Finance, 67(6), 2247-2293.

[5] Hellmann, T., \& Puri, M. (2002). Venture capital and the professionalization of start-up firms: Empirical evidence. The journal of finance, 57(1), 169-197.

[6] Kehrer, L. (2016). Genius (formerly Rap Genius). Genius Media Group, Inc. genius. com. Journal of the Society for American Music, 10(4), 518-520.

[7] Rastogi, N. I. T. A. N. K., \& Trivedi, M. K. (2016). PESTLE technique-a tool to identify external risks in construction projects. International Research Journal of Engineering and Technology (IRJET), 3(1), 384-388.

[8] Sammut-Bonnici, T., \& Galea, D. (2014). PEST analysis.

[9] Sahlman, W. A. (1996). Some thoughts on business plans. Harvard Business School Publ..

[10] Lim, D., \& Benson, A. R. (2020). Expertise and Dynamics within Crowdsourced Musical Knowledge Curation: A Case Study of the Genius Platform. arXiv preprint arXiv:2006.08108. 